\title{
Corrosion performance of reinforced mortar in the presence of polymeric nano-aggregates: electrochemical behavior, surface analysis, and properties of the steel/cement paste interface
}

\author{
J. Hu • D. A. Koleva $\cdot$ K. van Breugel
}

Received: 7 December 2011 / Accepted: 22 February 2012/Published online: 9 March 2012

(c) The Author(s) 2012. This article is published with open access at Springerlink.com

\begin{abstract}
This study reports on the effect of admixed polyethylene oxide- $b$-polystyrene $\left(\mathrm{PEO}_{113}-b\right.$ - $\left.\mathrm{PS}_{70}\right)$ micelles on corrosion behavior of reinforced mortar. The electrochemical measurement shows that the corrosion performance of the reinforcing steel was not significantly improved. However, surface analysis and microstructural investigation at the steel/cement paste interface reveal that the admixed micelles lead to a steel surface layer with enhanced barrier properties in terms of morphology and composition. Therefore, the presence of micelles further minimized and halted the corrosion process, despite the very aggressive, chloride-containing environment of $5 \% \mathrm{NaCl}$. The reasons and mechanisms behind the hereby observed corrosion behavior of reinforced mortar in the presence of micelles are related to the influence of these nano-aggregates on microstructural properties. These further results in altered water/ion transport and chloride-binding mechanisms in the bulk mortar matrix and thus steel product layer modifications towards enhanced corrosion resistance.
\end{abstract}

J. Hu $\cdot$ D. A. Koleva $\cdot$ K. van Breugel

Department Materials and Environment, Faculty of Civil

Engineering and Geosciences, Delft University of Technology,

Stevinweg 1, 2628 CN Delft, The Netherlands

J. $\mathrm{Hu}$

Key Laboratory of Specially Functional Materials

of the Ministry of Education, School of Materials Science and Engineering, South China University of Technology, Guangzhou 510640, People's Republic of China

\section{J. $\mathrm{Hu}(\square)$}

Department of Material Science, Faculty of CiTG, Delft

University of Technology, Stevinweg 1, 2628 CN Delft,

The Netherlands

e-mail: j.hu@tudelft.nl; jiehu0727@ hotmail.com

\section{Introduction}

Corrosion of steel reinforcement is considered to be the main reason of premature deterioration of reinforced concrete structures $[1,2]$. In the alkaline concrete environment (concrete pore solution, respectively) with a $\mathrm{pH}$ value between 12.6 and 13.5, the steel reinforcement is in a stable passive state $[3,4]$. Depassivation and corrosion initiation on the steel surface occur either when the $\mathrm{pH}$ of the pore solution drops to lower values $(\mathrm{pH}<9)$ due to carbonation [5], or when chloride ions have penetrated through the bulk concrete matrix and reached the reinforcement in a sufficiently high concentration to destroy the protective passive layer (reported values for total chloride concentration responsible for corrosion initiation vary between 0.2 and $2 \mathrm{wt} \%$ of dry cement [6,7]). The corrosion products occupy a volume several times larger than that of the original steel $[5,8]$, thus inducing cracking and spalling of the concrete cover and further affecting the service life of a reinforced concrete structure [5].

Various methods and techniques for corrosion control are available, including novel aspects in the field. In recent years, nano-sized particles are widely studied for their application in cement-based materials in terms of eventually improved material properties, e.g., mechanical performance [9-11], permeability [9, 12, 13], and microstructure of the matrix $[12,14]$. The incorporated nanoparticles are mainly inorganic materials, e.g., nano- $\mathrm{TiO}_{2}$ [15], nano- $\mathrm{SiO}_{2}[13,16]$, and/or nano- $\mathrm{Fe}_{2} \mathrm{O}_{3}$ [14]. A recent report on the application of nano-materials in concrete science [17] provides a comprehensive review on these aspects. Studies on the performance of concrete and/or reinforced concrete, containing organic nano-sized particles are, however, very restricted. Except reports on the influence of organic inhibitors [18-20] (although the aims 
and mechanisms related to inhibitors significantly differ from the hereby discussed phenomena and type of nanoaggregates), to our best knowledge, there is no record on the investigation of the corrosion performance of reinforced concrete in the presence of tailored polymeric nanoaggregates (e.g., micelles and/or vesicles).

This study is part of a larger research framework on a novel approach to corrosion control via self-healing. The self-healing mechanism essentially involves a controlled release of an active substance from admixed polymeric nano-aggregates. Considering the complicated nature and entirely different (than cement chemistry and electrochemistry) fields of application of these nano-structures, before "charging" them with certain "self-healing" agents, the influence of these nano-aggregates on electrochemical behavior of the reinforcing steel needs to be clarified through the application of "empty" formations, i.e., the hereby discussed micelles. This study for reinforced mortar followed several series of preliminary investigations, performed in a chronological order of studies in model solutions and plain mortar. A brief review on the latter, illustrating the motivation for further investigation and substantiating the objectives of this article will be given in what follows.

Preliminary investigations in model solutions, plain mortar, and reinforced mortar, admixed with polyethylene oxide $(\mathrm{PEO})_{113}-b$-polystyrene $(\mathrm{PS})_{218}$ micelles showed promising results in terms of increased corrosion resistance and significantly influenced bulk matrix properties [21-23]. Further, within more systematic studies, involving a modified variety of the nano-aggregates $\left(\mathrm{PEO}_{113}-b-\mathrm{PS}_{70}\right.$ micelles), the corrosion performance of carbon steel in cement extract (simulated concrete pore water) and material properties of plain mortar in the presence of micelles have been recently investigated [24, 25].

In cement extract [24], a very low concentration of the micelles in the corrosion medium $(0.0024 \mathrm{wt} \%)$ is able to initially increase the corrosion resistance of the carbon steel in the presence of $1 \% \mathrm{NaCl}$ and the pronounced effect only appeared at early stages, which was as expected to some extent, considering the very low concentration of micelles used. At early stages, the micelles adsorbed on the steel surface and altered the morphology and chemical composition of the formed products, a more uniform and compact layer, i.e., with increased barrier properties.

In plain mortar (cast with Ordinary Portland Cement OPC CEM I $42.5 \mathrm{~N}$, water-to-cement $(w / c)$ ratio $=0.5$, cement-to-sand $(c / s)$ ratio $=1: 3)$ [25], the results reveal that although the admixed micelles did not significantly influence the compressive strength of the mortar, even a very low concentration of micelles $(0.025 \mathrm{wt} \%$ of dry cement) significantly reduced the porosity ( $40 \%$ reduction) and water permeability (three orders of magnitude lower) of the matrix.

These preliminary investigations lead to the conclusion that the corrosion resistance of reinforcing steel, embedded in mortar (concrete) will be possibly increased if micelles (i.e., aggregates which do not carry any active substance yet) are present in the matrix. The expectation results from the fact that in the presence of micelles, the reduced permeability [22, 25] will lead to a reduced chloride penetration and corrosion initiation, respectively, will be delayed. Further, in the event of chloride arrival at the steel/cement paste interface, the presence of micelles would even further halt corrosion propagation due to maintained superior properties of the passive layer (as this was observed for earlier stage in model liquid environment, [24]). To this end, this article reports on the integration of electrochemistry and concrete material science for a thorough evaluation of a reinforced mortar system modified with the same type of micelles $\left(\mathrm{PEO}_{113}-b-\mathrm{PS}_{70}\right)$ in comparison to non-modified such in control (non-corroding) and corroding conditions.

\section{Experimental}

Reinforced mortar cylinders and cement paste specimens

Ordinary Portland cement OPC CEM I $42.5 \mathrm{~N}$ (ENCI, Table 1) was used to prepare the reinforced mortar and cement paste specimens in this study. The water-to-cement $(w / c)$ ratio was 0.5 for both cement paste and mortar and the cement-to-sand ratio was 1:3 for mortar. For the micelles-containing specimens, the "as-received" micelles solution was used as the mixing water instead of tap water $\left(\mathrm{PEO}_{113}-b-\mathrm{PS}_{70}\right.$ micelles were previously dissolved in demineralized-water with a concentration of $0.5 \mathrm{~g} / \mathrm{l}$.) The micelles concentration in the mortar and the cement paste was thus $0.025 \mathrm{wt} \%$ of dry cement.

The reinforced mortar cylinders had dimensions: $H=150 \mathrm{~mm}, D=35 \mathrm{~mm}$, and contained a centrally embedded construction steel bar (FeB500HKN steel, $d=8 \mathrm{~mm}$, used as received; exposed active surface area of $30 \mathrm{~cm}^{2}$; composition according NEN6008 (in wt\%): C $<0.12$, Si max 0.6, $\mathrm{P} \max 0.05, \mathrm{~S} \max 0.05, \mathrm{~N} \max 0.012$ ). All specimens were cured in a fog room $\left(20{ }^{\circ} \mathrm{C}\right.$ and $98 \%$ relative humidity) for 28 days and further lab conditioned (in tap water for control cases or $5 \% \mathrm{NaCl}$ solution for corroding cases, respectively) until the end of the testing period of 86 days (the experimental set-up is as previously used and reported in [26, 27]). There were three monitored replicates for each group and relevant test procedure. 
Table 1 Chemical composition of OPC CEM I 42.5 N (ENCI, NL) and mixing proportions for the reinforced mortar cylinders

\begin{tabular}{llllllllllll}
\hline Oxide & $\mathrm{CaO}$ & $\mathrm{SiO}_{2}$ & $\mathrm{Al}_{2} \mathrm{O}_{3}$ & $\mathrm{SO}_{3}$ & $\mathrm{Fe}_{2} \mathrm{O}_{3}$ & $\mathrm{MgO}$ & $\mathrm{Na}_{2} \mathrm{O}$ & $\mathrm{K}_{2} \mathrm{O}$ & $\mathrm{TiO}_{2}$ & $\mathrm{P}_{2} \mathrm{O}_{5}$ & $\mathrm{Mn}_{3} \mathrm{O}_{4}$ \\
\hline Weight $(\%)$ & 64.40 & 20.36 & 4.96 & 2.57 & 3.17 & 2.09 & 0.14 & 0.64 & 0.35 & 0.18 & 0.14 \\
\hline
\end{tabular}

Mixing proportions: $w / c$ ratio $0.5 ; c / s$ ratio $1: 3$; mixing and casting according to EN 196-1

The cement paste mixture was tightly sealed in plastic bottles after casting. After rotation for $24 \mathrm{~h}$, the samples were cured in sealed condition at room temperature. At 7 days hydration age, the hydration of the cement paste was stopped by submerging in liquid nitrogen and the specimens were then placed in a freeze-dryer at $-28{ }^{\circ} \mathrm{C}$ until reaching a constant weight (the sample preparation procedure was previously reported in [28, 29]).

Sample designation

For reinforced mortar, group "Ref" represents the specimens cast with tap water, "Nano" represents the specimens cast with the micelles solution. The specimens were immersed in tap water for "control" groups or in $5 \% \mathrm{NaCl}$ solution for corroding groups, respectively. Thus, there were totally four groups in this study: control groups are designated as "Ref" and "Nano;" corroding groups are designated as "RefN" and "NanoN." For cement paste, there were two groups of specimens: specimens "OPC," representing the samples cast with tap water, and specimens "OPCm," representing the samples cast with the micelles solution.

\section{Polymeric nano-aggregates}

The nano-aggregates used in this study were prepared from $\mathrm{PEO}_{113}-b$-PS 70 diblock copolymer. The copolymer was synthesized by atom transfer radical polymerization (ATRP), employing the macroinitiator technique [30-32]. The copolymers were dissolved in dioxane, which is a common solvent for the two blocks. Demineralized-water, which is a good solvent for PEO and non-solvent for PS blocks, was then added drop-wise to gradually replace the organic solvent. The addition of approximately $8 \mathrm{v} / \mathrm{v} \%$ $\mathrm{H}_{2} \mathrm{O}$ to the copolymer solution in dioxane triggered spontaneous self-assembly leading to minimization of the contact between the insoluble PS blocks and the water molecules in the system. After dialysis, an opalescent aqueous dispersion associated with the formation of coreshell micelles was obtained. The $\mathrm{PEO}_{113}-b-\mathrm{PS}_{70}$ micelles are amphiphilic formations, presenting a hydrophilic PEO "shell" and a hydrophobic PS "core." The hydrodynamic radius of the micelles was approximately $50 \mathrm{~nm}$, identified by dynamic light scattering (DLS) measurement [24].
Experimental methods

\section{Electrochemical methods}

Electrochemical impedance spectroscopy (EIS) and potentiodynamic polarization (PDP) were employed, using a common three-electrode cell arrangement, the steel bar serving as the working electrode and MMO Ti mesh served as a counter electrode (the set-up is as generally used and reported [26, 27]). All results from electrochemical measurements (performed in immersed condition) are reported with respect to a saturated calomel electrode (SCE); all measurements were performed after stabilization of open circuit potential (OCP); the PDP measurements were performed in the range of -0.2 to $+1.2 \mathrm{~V}$ versus OCP at a scan rate $0.5 \mathrm{mV} / \mathrm{s}$ after OCP stabilization; The EIS measurements were carried out in the frequency range of $50 \mathrm{kHz}$ to $10 \mathrm{mHz}$ by superimposing an ac voltage of $10 \mathrm{mV}$. The used equipment was EcoChemie AutolabPotentiostat PGSTAT30, combined with FRA2 module, using GPES and FRA interface.

\section{Surface analysis (steel reinforcement)}

At the end of the study (after 86 days of conditioning), the morphology and the composition of the product layers, formed on the steel surface were investigated using X-ray diffraction (XRD) and scanning electron microscopy (SEM), coupled with energy dispersive X-ray (EDX) analysis. XRD analysis was performed by scanning the surface of the test specimen, using D8 Advance Diffractometer, "Bruker AXS." A VANTEC position sensitive detector (window 6 degree) was used for detection. Energy source was Co $\mathrm{K} \alpha(1.789 \AA)$ and the tube settings were $45 \mathrm{kV}$ and $35 \mathrm{~mA}$. SEM and EDX investigations were performed with an environmental SEM, ESEM Philips XL 30, equipped with EDX detector. The EDX was used as a qualitative and semi-quantitative analysis both on the steel surface and in the adjacent cement paste. EDX spot analysis was conducted (using local area of $5 \times 5 \mu \mathrm{m}$ at magnification of $2000 \times$ ) in radial direction of the steel bar (results are an average of four radial directions), starting at point $10 \mu \mathrm{m}$ (the steel/cement paste interface) up to $3000 \mu \mathrm{m}$ into the bulk material (direction the edge (mortar cover) of the specimen). 
Microstructural analysis of bulk matrix and steel/cement paste interface

The analysis is based on ESEM micrographs (captured using BSE detector) and image processing was performed using OPTIMAS software. The results from image analysis are an average value of 35 locations per sample in each specimen both for the bulk matrix and for the steel/cement paste interface. The physical size for the reference region of each image is $226 \mathrm{~mm}$ in length and $154 \mathrm{~mm}$ in width, with resolution of $0.317 \mathrm{~mm} /$ pixel, corresponding to a magnification of $500 \times$; the sample preparation and relevant procedures are as reported elsewhere [28, 29, 33, 34]. ESEM imaging combined with quantitative image analysis provides microstructural information of pore space, e.g., porosity and pore size distribution (more details are reported in $[28,33,35,36])$. The image analysis in this study complies with generally used methodology for pore structure analysis of cement-based materials [28, 29, 33, 37].

\section{Nano-indentation}

Agilent Nano Indenter G200 was used for nano-indentation tests to determine the elastic modulus $E$ of different phases [e.g., un-hydrated cement particles and calcium silicate hydrate (CSH)]. The local mechanical properties of the matrix can be determined from the indentation load and displacement measurement. The sample preparation included grounding of the surfaces of the specimens with silicon carbide papers and polishing with diamond powders spray to obtain a very flat and smooth surface. After polishing, the specimens were cleaned in an ultrasonic bath. Information on the mechanical properties was obtained from a matrix of a minimum of 105 indents covering a representative area of at least $40 \times 200 \mu \mathrm{m}^{2}$ on the surface. Three locations per specimen (in an area of $904 \times 616 \mu \mathrm{m}^{2}$ ) were tested in this study. The selected indent spacing was $10 \mu \mathrm{m}$. The indentation depth was $1 \mu \mathrm{m}$. A Berkovich tip was used for the indentation. The Continues Stiffness Method (CSM) developed by Oliver and Pharr [38] was used for the analysis of the results and the average $E$-modulus was determined in the loading range between 200 and $800 \mathrm{~nm}$ depths.

\section{Results and discussion}

Electrochemical response

\section{$O C P$ and $P D P$}

Well known is the assessment for passive or active state of steel in reinforced cement-based materials via monitoring the OCP values with time of conditioning, which also determines the time to corrosion initiation. For a reinforced mortar system, the potential threshold of passivity is generally accepted as $-200 \pm 70 \mathrm{mV}[39,40]$. The steel is in passive state if the OCP is equal or more anodic then this value. Figure 1 presents the OCP readings for all specimens at different time intervals (readings are the average value of three replicates per condition; deviations are also shown in the plot). For the control specimens (immersed in tap water), the OCP values were always more anodic than $-200 \mathrm{mV}$ (SCE) for both specimens RefW and NanoW, meaning that the steel reinforcement was in passive state. For the corroding specimens (immersed in $5 \% \mathrm{NaCl}$ solution), the recorded OCP values for the micelle-free specimen (RefN) shifted cathodically at the stage of $\sim 30$ days, whereas for the micelle-containing specimen (NanoN), corrosion activity according OCP values was recorded on slightly later stages ( $\sim 42$ days), i.e., although the environmental medium is quite more aggressive, compared to real conditions $(5 \% \mathrm{NaCl}$ for the former case compared to $3-3.5 \% \mathrm{NaCl}$ as generally accepted to represent sea-water environment) the admixed micelles did not exert a very significant corrosion delay, at least according to potential readings.

In order to quantitatively assess the corrosion state of the steel reinforcement, PDP tests were performed on (separate) replicates from each investigated group. The tests were performed at immersion stages where, according to OCP readings, pronounced differences were expected. Figure 2a depicts an overlay for control specimens RefW and NanoW and Fig. $2 b$ presents an overlay of PDP curves for corroding specimens RefN and NanoN at 28, 42, and 86 days, respectively. As seen from the plots, no significant difference was observed in corrosion and anodic current densities for the control cases, which is expected since all these specimens are in passive state (corrosion current density was in the range of $0.015-0.065 \mu \mathrm{A} / \mathrm{cm}^{2}$ and the $I_{\text {corr }}$ threshold value for passivity is generally accepted as $0.1 \mu \mathrm{A} / \mathrm{cm}^{2}$ [41]). Slightly more noble potentials and lower

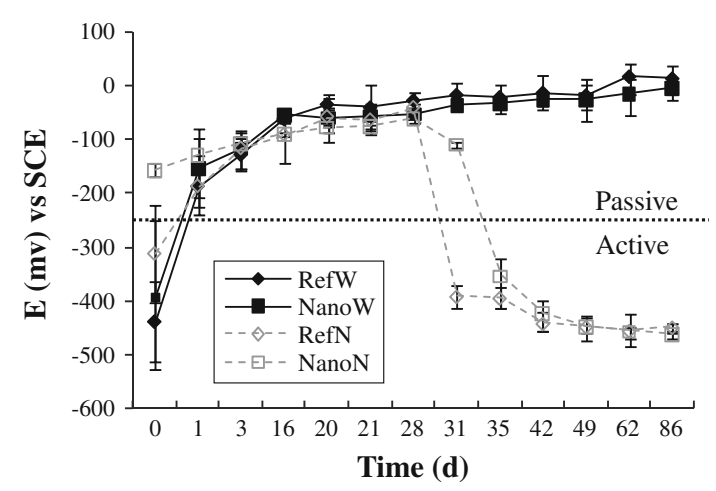

Fig. 1 OCP readings of all specimens at different time intervals 

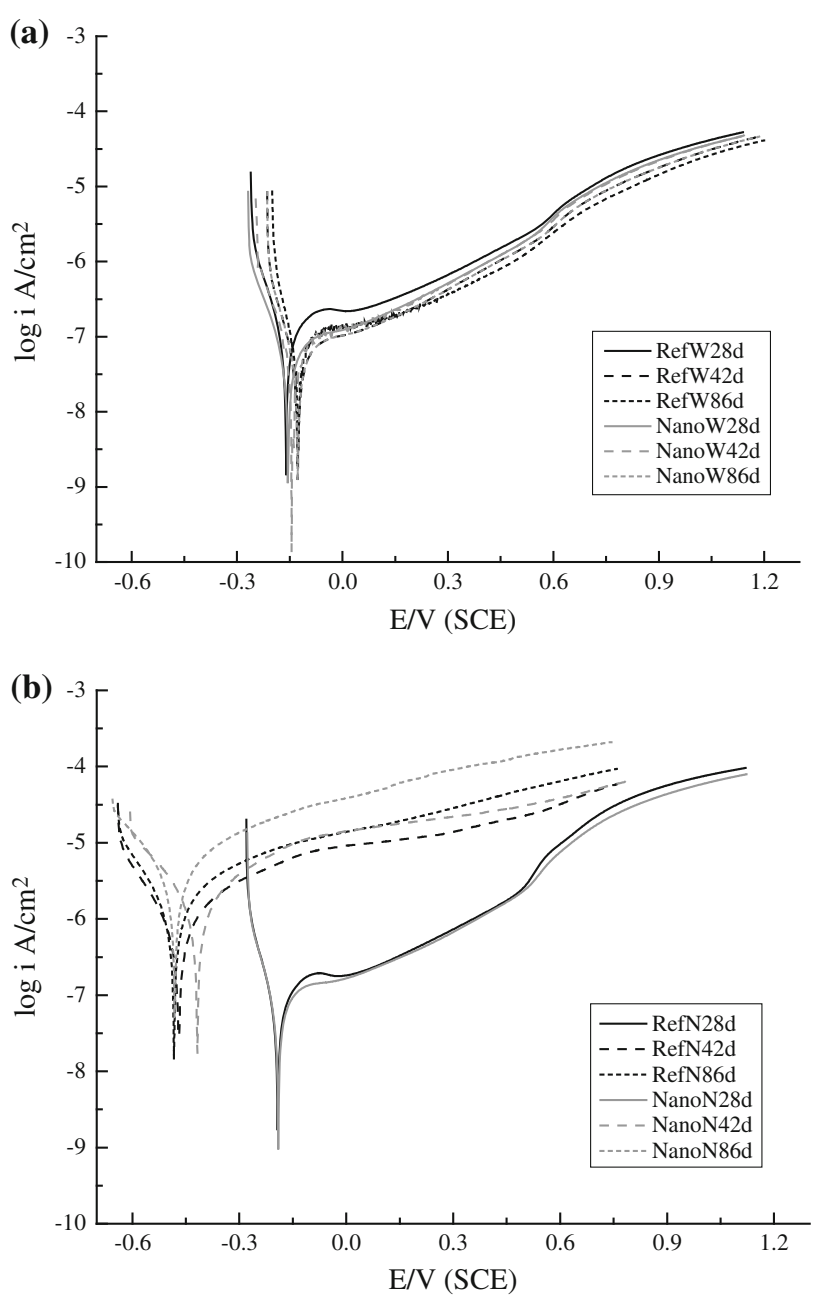

Fig. 2 PDP curves for the embedded steel: a control specimens and b corroding specimens

anodic currents were recorded for specimen NanoW, denoted to diffusion limitations with anodic polarization, most likely resulting from increased barrier effects of the passive layer in the presence of micelles. Similarly, but in a higher current density range (in the range of $0.065-0.95$ $\mu \mathrm{A} / \mathrm{cm}^{2}$ for specimen RefN and $0.052-1.24 \mu \mathrm{A} / \mathrm{cm}^{2}$ for specimen NanoN), the corroding specimens show no significant difference with external polarization, except the more anodic corrosion potentials for specimens NanoN (Fig. 2b). Anodic current densities are even slightly higher, compared to the micelle-free corroding specimen RefN. Apparently no obvious improvement of corrosion resistance as a result of the presence of the micelles in the bulk matrix can be observed at this stage. This behavior was not according to the expectations and to further elucidate the recorded electrochemical response with external polarization, impedance spectroscopy was employed, aiming at gaining information for both corrosion resistance and the contribution of the bulk matrix properties.
Electrochemical impedance spectroscopy (EIS)

EIS is widely used for investigating the corrosion processes in a reinforced concrete system [42-44] and is able to give information for both the steel surface (electrochemical parameters) and the concrete bulk matrix (concrete bulk, pore network resistance) [45-48]. The EIS measurements in this study were performed at certain time intervals for all investigated. As an example of experiment-fit procedure and the relevant error plot, Fig. 3a presents the experimental EIS response, the fitted curves and the used equivalent circuit (including best fit parameters) for specimen RefN at the stage of 86 days. Figure $3 \mathrm{~b}$ gives the relevant error plot.

The hereby used equivalent circuit $\left(R_{\mathrm{el}+b}\left(Q_{\mathrm{pn}}\left[R_{\mathrm{pn}}\right.\right.\right.$ $\left.\left.\left(Q_{\mathrm{ct}} R_{\mathrm{ct}}\right)\right]\right)$, Fig. 3a, comprises two time constants in series with the electrolyte resistance (the circuit is as previously used and reported for reinforced mortar [26, 33]). The elements of the equivalent circuit present the following physical meanings: $R_{\mathrm{el}+b}$ is the mortar resistance, including the contribution of the electrolyte resistance; the first time constant $\left(R_{\mathrm{pn}}\right.$ and $\left.Q_{\mathrm{pn}}\right)$ is attributed to the properties of the bulk matrix in terms of connected pore network; the second time constant $\left(Q_{\mathrm{ct}}\right.$ and $\left.R_{\mathrm{ct}}\right)$ is normally used to evaluate charge transfer process in combination with mass transport process. When there are no mass transport limitations, $R_{\mathrm{ct}}$ equals the global polarization resistance $R_{\mathrm{p}}[35,45]$ and is related to the electrochemical reaction on the steel surface (widely accepted for reinforced cement-based materials is to use constant phase element $(Q)$ instead of pure capacitance to account for steel surface, product layers, and bulk matrix heterogeneity [49, 50]).

A non-ideal capacitive response is hereby denoted not only to heterogeneity of hydration/corrosion products on the steel surface but also including the contribution of the admixed micelles for the case of specimens NanoW and NanoN. Well known is that $Q$ may be viewed as resembling a capacitor-resistor series combination in which both components have frequency-dependent values. It is defined as [47, 51]: $Z=1 / Y_{0}(j \omega)^{n}$, where $Y_{0}$ is the base admittance with units of $\Omega^{-1} \mathrm{~s}^{\mathrm{n}}$. When $n=1, Q$ simplifies an ideal capacitor (when $n=0, Q$ simplifies a pure resistor); when $0<n<1$, characteristic is a non-ideal capacitive response.

The EIS response was recorded for all specimens on time intervals until 86 days. The response was similar within the specimens: Figs. 4 and 5 present the experimental data for the control and corroding cases as an overlay of results per immersion stage (i.e., an overlay of 28,42 , and 86 days; the plots present values in $\mathrm{k} \Omega$, since the geometry of the specimens and the steel surface were identical). The best fit parameters are summarized in Table 2. 
Fig. 3 a EIS response and fit treatment: $E_{\mathrm{OCP}}=-439 \mathrm{mV}$; $R_{\mathrm{el}+b}=18.37 \mathrm{k} \Omega \mathrm{cm}^{2}$;

$Q_{\mathrm{pn}}=4.65 \mathrm{E}-08 ; n=0.37$; $R_{\mathrm{ct}}=35.18 \mathrm{k} \Omega \mathrm{cm}^{2}$;

$Q_{\mathrm{ct}}=9.91 \mathrm{E}-04 ; n=0.68$; b error plots for specimen RefN, 86-day treatment for specimen RefN, 86-day $R_{\mathrm{pn}}=7.33 \mathrm{k} \Omega \mathrm{cm}^{2}$;
Fig. 4 EIS responses in Nyquist and Bode format for control specimens
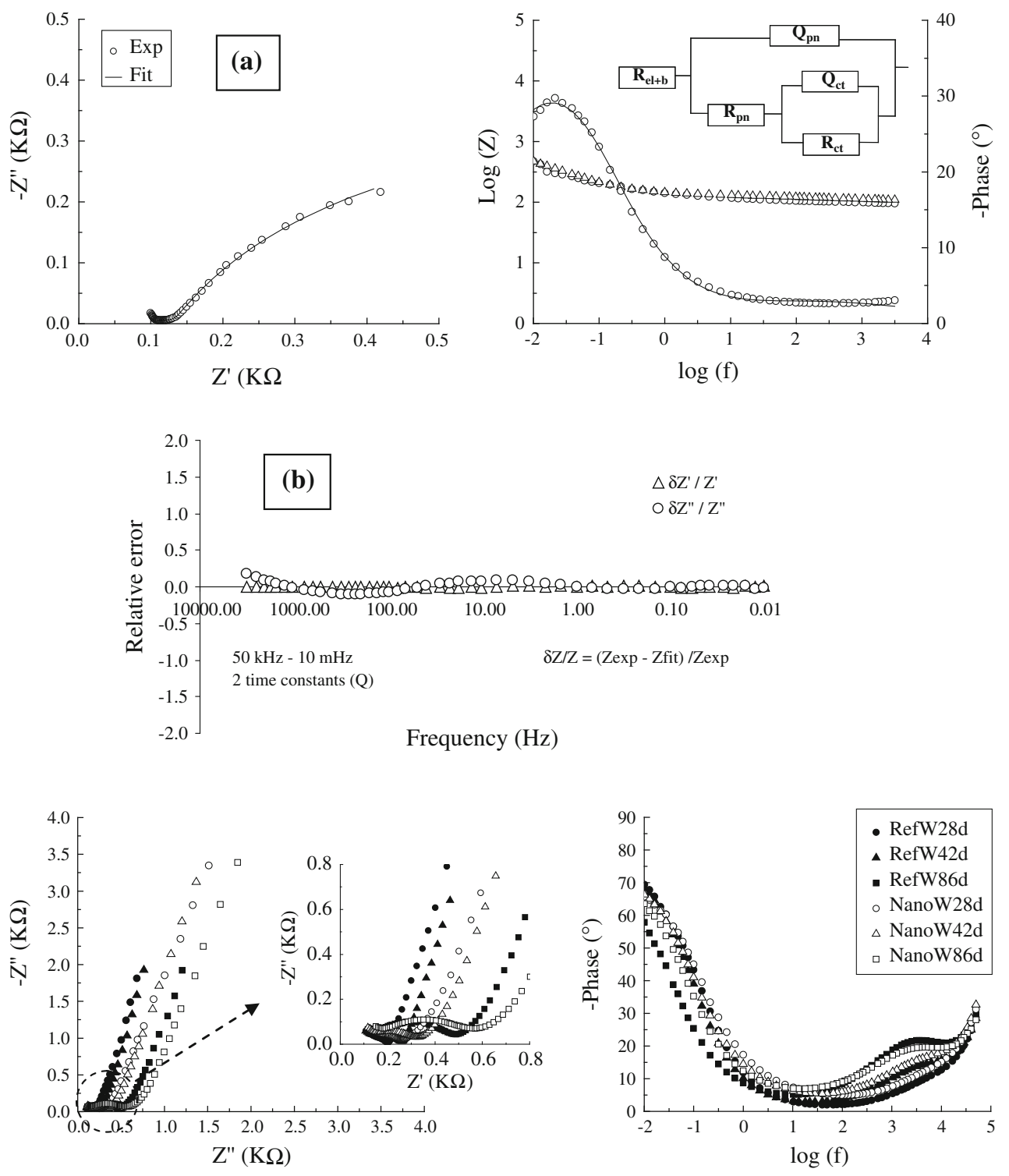

Fig. 5 EIS responses in Nyquist and Bode format for corroding specimens

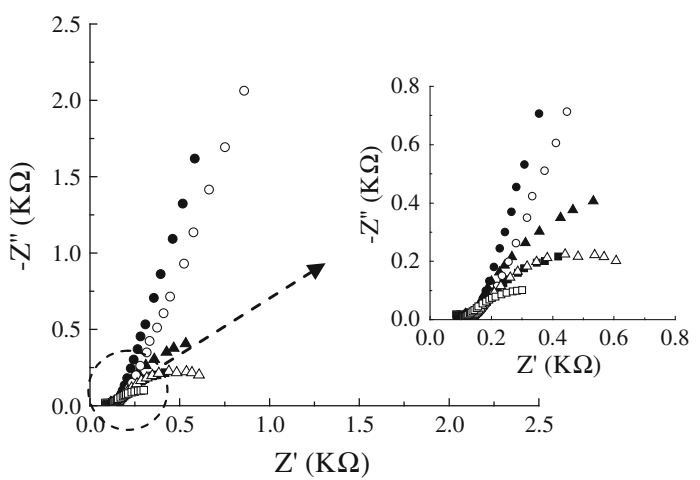

The shape of the experimental curves for all specimens reflects typical response of steel reinforcement in the alkaline medium of concrete and in conditions of chloride present at the steel/cement paste interface [52, 53]. The response in the high frequency domain is related to the mortar bulk resistance in terms of connected pore network, including the electrolyte resistance $\left(R_{\mathrm{el}+b}\right.$ and $\left.R_{\mathrm{pn}}\right)$ [47]. For the control cases, the bulk matrix resistance for the 
Table 2 Best fit parameters from experimental EIS results in reinforced mortars equivalent electrical circuit (two time constants): $R_{\mathrm{el}+b}\left(Q_{\mathrm{pn}}\left[R_{\mathrm{pn}}\left(Q_{\mathrm{ct}} R_{\mathrm{ct}}\right)\right]\right)$

\begin{tabular}{lllllllll}
\hline Sample & Time (days) & $R_{\mathrm{el}+b}\left(\mathrm{k} \Omega \mathrm{cm}^{2}\right)$ & $Q_{\mathrm{pn}}, Y_{0}\left(\Omega \mathrm{s}^{n-1}\right)$ & $n$ & $R_{\mathrm{pn}}\left(\mathrm{k} \Omega \mathrm{cm}^{2}\right)$ & $Q_{\mathrm{pn}}, Y_{0}\left(\Omega \mathrm{s}^{n-1}\right)$ & $n$ & $R_{\mathrm{ct}}\left(\mathrm{k} \Omega \mathrm{cm}^{2}\right)$ \\
\hline RefW & 28 & 19.42 & $1.50 \mathrm{E}-08$ & 0.6489 & 18.06 & $1.11 \mathrm{E}-03$ & 0.7861 & 221.20 \\
& 42 & 29.71 & $1.77 \mathrm{E}-08$ & 0.6225 & 19.09 & $1.12 \mathrm{E}-03$ & 0.7933 & 220.27 \\
& 86 & 71.55 & $1.18 \mathrm{E}-08$ & 0.6104 & 21.87 & $3.33 \mathrm{E}-04$ & 0.7286 & 217.99 \\
\multirow{2}{*}{ NanoW } & 28 & 29.64 & $6.14 \mathrm{E}-09$ & 0.5248 & 22.46 & $2.04 \mathrm{E}-04$ & 0.7236 & 293.57 \\
& 42 & 40.81 & $7.17 \mathrm{E}-09$ & 0.5254 & 26.80 & $3.63 \mathrm{E}-04$ & 0.7578 & 304.51 \\
& 86 & 84.05 & $5.90 \mathrm{E}-09$ & 0.5708 & 30.28 & $1.02 \mathrm{E}-04$ & 0.6898 & 356.49 \\
RefN & 28 & 22.26 & $2.56 \mathrm{E}-08$ & 0.5544 & 2.98 & $1.73 \mathrm{E}-03$ & 0.8172 & 200.46 \\
& 42 & 18.68 & $1.27 \mathrm{E}-08$ & 0.3958 & 5.39 & $2.24 \mathrm{E}-03$ & 0.7584 & 47.63 \\
& 86 & 18.37 & $4.65 \mathrm{E}-08$ & 0.3671 & 7.33 & $9.91 \mathrm{E}-04$ & 0.6763 & 35.18 \\
NanoN & 28 & 20.75 & $7.08 \mathrm{E}-08$ & 0.5276 & 4.42 & $4.32 \mathrm{E}-04$ & 0.7355 & 238.72 \\
& 42 & 19.83 & $3.00 \mathrm{E}-08$ & 0.4053 & 6.10 & $5.78 \mathrm{E}-04$ & 0.7087 & 26.56 \\
& 86 & 15.96 & $6.92 \mathrm{E}-08$ & 0.3508 & 6.74 & $4.11 \mathrm{E}-04$ & 0.5920 & 15.80 \\
\hline
\end{tabular}

micelles-containing specimens is slightly higher at the end of the testing period $\left(\sim 110 \mathrm{k} \Omega \mathrm{cm}^{2}\right)$, compared to the micelle-free such $\left(\sim 90 \mathrm{k} \Omega \mathrm{cm}^{2}\right)$, as well as throughout the test (Table 2). For the corroding specimens, similar bulk matrix resistance values were recorded (in the range of $16-18 \mathrm{k} \Omega \mathrm{cm}^{2}$ after 86 days of conditioning). It is well known that the bulk matrix resistance is closely related to microstructural properties of the mortar. The effect of the admixed micelles was previously proved to be in terms of reduced porosity and water permeability, which is not necessarily the case when chlorides are involved [21, 22, 25]. Therefore, the control specimens present the expected behavior (higher resistance for the micelle-containing specimens), whereas the corroding such, are similar in bulk matrix characteristics. The related phenomena will be discussed further in section "Microstructural analysis of bulk matrix and steel/cement paste interface."

Further, the electrochemical behavior of the steel reinforcement is derived from the middle-low frequency domain. The EIS response for all specimens is consistent with the previously discussed results from PDP measurements, i.e., the control cases present high corrosion resistance $\left(R_{\mathrm{ct}}\right.$ values in the range of $220-350 \mathrm{k} \Omega \mathrm{cm}^{2}$, the higher values were recorded in the presence of micelles), whereas similarly low $R_{\mathrm{ct}}$ values were recorded for both micelle-free (RefN) and micelle-containing (NanoN) specimens (20-35 $\mathrm{k} \Omega \mathrm{cm}^{2}$ at 86 days). Consequently, here again, no significant improvement of the corrosion behavior was observed when micelles are admixed in the reinforced mortar (except at very early stage for specimens NanoN and throughout the test for specimens NanoW, the latter, however, being control cells).

Considering the previous reports for the positive influence of the micelles on bulk matrix characteristics (i.e., reduced porosity, permeability, etc. [25]), as well as increased corrosion resistance and superior properties of the steel surface product layers in model solutions [24], the above-presented electrochemical behavior of steel in micelle-modified mortar is not as expected. Moreover, microstructural analysis of the bulk matrix and evaluation of the properties of the steel/cement paste interface, as well as surface analysis of the steel surface, show indeed modified matrix for the micelle-containing reinforced mortar and none or much less corrosion product accumulation on the steel surface. These aspects will be presented in the following sections and the most plausible reasons and phenomena for the observed behavior will be discussed.

Microstructural analysis of bulk matrix and steel/cement paste interface

The purpose of this analysis is to evaluate the microstructural characteristics as porosity and critical pore size both for the bulk matrix (the area beyond the distance of $250 \mu \mathrm{m}$ away from the steel surface) and for the steel/ cement paste interface (the area within a distance of $50 \mu \mathrm{m}$ away from the steel surface) at the top, middle, and bottom sections of the reinforced mortar cylinders; these parameters are further "translated" into more global properties as permeability or pore network connectivity. These in turn will provide information for the easiness of water and $\mathrm{NaCl}$ permittivity in the matrix, i.e., in general a denser matrix and reduced critical pore size and pore network interconnectivity would denote for reduced or delayed chlorideinduced corrosion initiation and propagation. Further, as previously introduced, the presence of micelles in plain mortar resulted in a significant reduction of porosity and water permeability [22, 25] which was expected also to be the case for the hereby investigated reinforced mortar. 

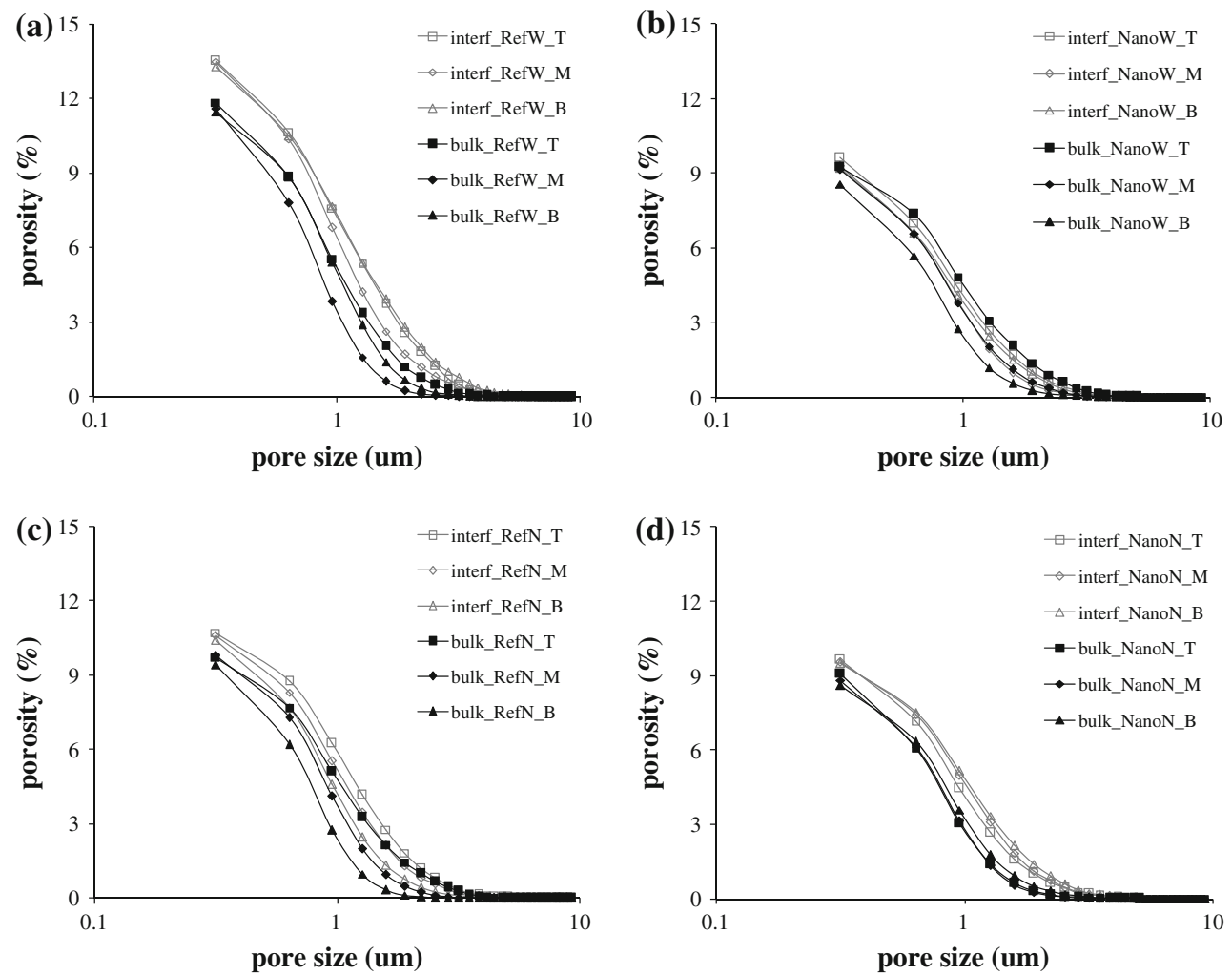

Fig. 6 Calculated porosity and pore size distribution for the bulk matrix and the steel/cement paste interface of all specimens at the conditioning time of 86 days. a RefW, b NanoW, c RefN, and d NanoN

In this study, the microstructural parameters depend on: cement hydration with aging; the presence of chloride in the corroding specimens (chloride is generally known to accelerate cement hydration and cause initial densification of the bulk matrix [36]); the corrosion process itself (volume expansion of corrosion products) $[33,36]$ and the admixed micelles. The calculated porosity and pore size distribution for the both bulk matrix and steel/cement paste interface for all specimens are shown in Fig. 6 (hydration age of 86 days).

As can be clearly observed from the plots, the presence of micelles leads to reduced porosity and pore size distribution for both control and corroding specimens (compare Fig. 6 left with right). Further, the cement matrix at the steel/cement paste interface was slightly more porous for both specimens when compared to that of the bulk matrix, evidenced by higher porosity derived at the interface region. However, the micelles-containing specimen NanoW had a more uniform porosity distribution with a smaller porosity gradient in the radial direction of the reinforced mortar cylinder (Fig. 6). This confirms that the admixed micelles are able to refine the pore network, i.e., reduce the porosity at the steel/cement paste interface and also cause pore refinement in the bulk matrix. This is consistent with previous results for plain mortar in the presence of micelles [25]. For the corroding cases, the influence of micelles is less pronounced, resulting in most likely similar susceptibility to chloride-induced corrosion initiation as a result of chloride penetration to the steel surface. This fact is also supported and evidenced from electrochemical measurements, where similarly active behavior was observed for micelles-free and micellescontaining specimens. The remaining question is why corrosion performance was not as significantly improved as expected. On one hand, indeed, the concentration of micelles is very low, so any effect would be pronounced within short terms and will further vanish (as was recorded in model solutions [24]). On the other hand, the product layers' composition and accumulation of corrosion products on the steel surface in the hereby investigated micellecontaining mortar were different from the micelle-free ones (Figs. 7, 8, 9, 10 present the steel surface analysis). Therefore, if corrosion after once initiated is further halted or minimized (as actually hereby observed, section "XRD, SEM, and EDX analyses on the steel surface"), which is due to better properties of the product layer in the presence of micelles, or due to repair of the product layer (possible repassivation), the hereby monitored time intervals (of max 86 days) are not sufficient to show and prove the positive effect that was expected. 
Fig. 7 XRD patterns for all specimens after conditioned for 86 days (using Co $\mathrm{K} \alpha$

radiation). $C$ calcite, $G$ goethite, $M G$ magnetite, $Q$ quartz (relicts from sand/bulk matrix),

$W$ wustite, $A r$ aragonite,

$P$ portlandite, $H$ hematite. a RefW, b NanoW, c RefN, and d NanoN
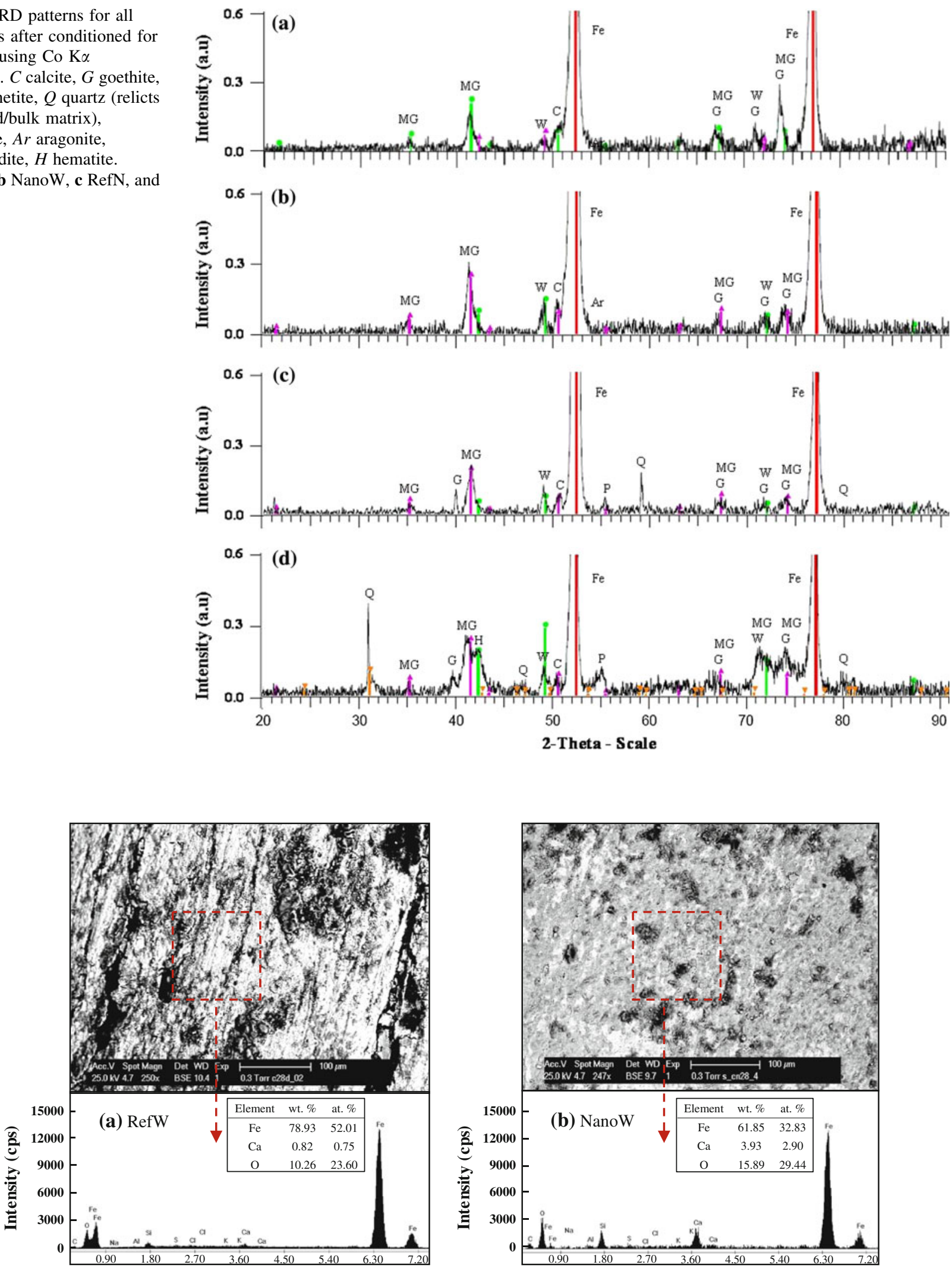

Fig. 8 Morphology observation and EDX analysis of steel surface for control specimens after conditioned for 86 days (the table shows the concentration of most relevant elements in wt $\%$ and at.\%) 

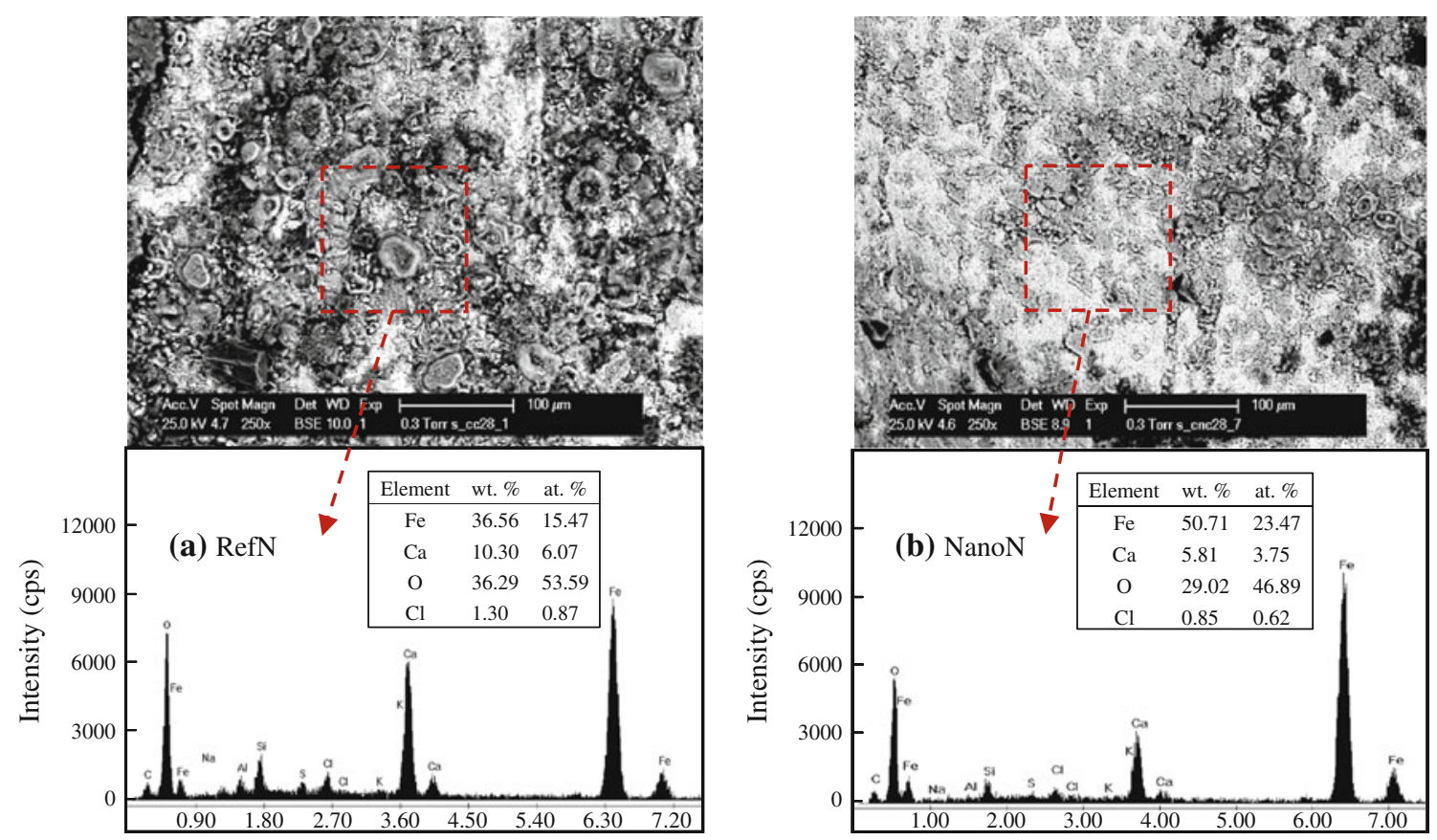

Fig. 9 Morphology observation and EDX analysis of steel surface for corroding specimens after conditioned for 86 days (the table shows the concentration of most relevant elements in wt $\%$ and at.\%)

XRD, SEM, and EDX analyses on the steel surface

After lab conditioned for 86 days, the reinforced mortar cylinders were broken, and the product layers formed on the steel surface in each group were investigated by XRD analysis (using Co $\mathrm{K} \alpha$ radiation on a representative area of about $1 \mathrm{~cm}^{2}$ steel surface), which is shown in Fig. 7 (the peaks of iron are truncated to highlight the intensity signals of various products).

The common products on a steel surface, previously conditioned in cement-based materials, include except a mixture of iron oxides/hydroxides [wustite $(\mathrm{FeO}$, as part of $\left.\mathrm{FeO} \cdot \mathrm{Fe}_{2} \mathrm{O}_{3}\right)$, hematite $\left(\mathrm{Fe}_{2} \mathrm{O}_{3}\right)$, magnetite $\left(\mathrm{Fe}_{3} \mathrm{O}_{4}\right)$, goethite $(\alpha-\mathrm{FeOOH})]$, also portlandite $\left(\mathrm{Ca}(\mathrm{OH})_{2}\right)$ and calcite/aragonite $\left(\mathrm{CaCO}_{3}\right)$, corresponding to Ca-substituted iron oxides/hydroxides on the steel surface (it is well known that the Ca-substituted layers provide better corrosion resistance [35, 45]). For the control specimens, similar features and peak intensity of the XRD patterns were observed, mainly featuring wustite ( $\mathrm{W}$, as part of $\mathrm{MG}$ ), corresponding to peaks $2 \theta 49.2^{\circ}$ [54] and magnetite (MG), corresponding to peaks $2 \theta 35.5^{\circ}$ and $41.6^{\circ}$, respectively $[54,55]$. For the corroding specimens, the main difference appears to be in the amounts of goethite $(\mathrm{G})$, hematite $(\mathrm{H})$, and $\mathrm{MG}$ for specimens NanoN (overlaid peaks between $2 \theta 39^{\circ}$ and $44^{\circ}$ and between $2 \theta 70^{\circ}$ and $76^{\circ}$ ), presenting wider and higher intensity peaks, compared to the corresponding ones for specimen RefN. Additionally, the portlandite $(\mathrm{P})$ peak at $2 \theta$ $55^{\circ}$ is more pronounced for NanoN. Therefore, the products for the micelles-containing specimen contribute to a more protective and adherent layer (enriched in $\mathrm{MG}, \mathrm{H}$, and Ca-substituted such) on the steel surface, compared to the micelles-free specimen. The XRD results are supported (and "visualized") by direct ESEM observations and EDX analysis on the steel surface. Figure 8 depicts micrographs of the control cases, where relatively clean surface was observed for specimen RefW (Fig. 8a) whereas a more compact, denser, and homogeneous Ca-rich layer was observed for specimens NanoW (Fig. 8b). The observation is consistent with the lower intensity of $\mathrm{G}$ and W/MG peaks in specimen NanoW (Fig. 7), i.e., Ca-containing compounds are adhered to the steel surface.

Corrosion products have formed for both corroding specimens RefN and NanoN, Fig. 9. The corrosion products for specimen RefN occupied significantly larger surface area and were chloride-containing (Fig. 9a). In contrast, only isolated locations on the surface of specimen NanoN were covered by corrosion products of lower dimensions and crystallinity.

Although the corrosion product layer appeared to be of superior properties $\left(\mathrm{Fe}_{2} \mathrm{O}_{3}, \mathrm{Fe}_{3} \mathrm{O}_{4}\right.$, and $\mathrm{Ca}$-substituted such), apparently corrosion was initiated in specimens NanoN. Further, the similar microstructural properties for specimens RefN and NanoN denote for similar permeability and access to chloride penetration. Therefore, according to the correlation of electrochemical measurements, surface 
Fig. 10 Cross-sectional images of steel/cement paste interface for top, middle, and bottom sections of the corroding specimens RefN and NanoN after conditioned for 86 days (the locations for EDX point analysis were marked as "•" in the images)
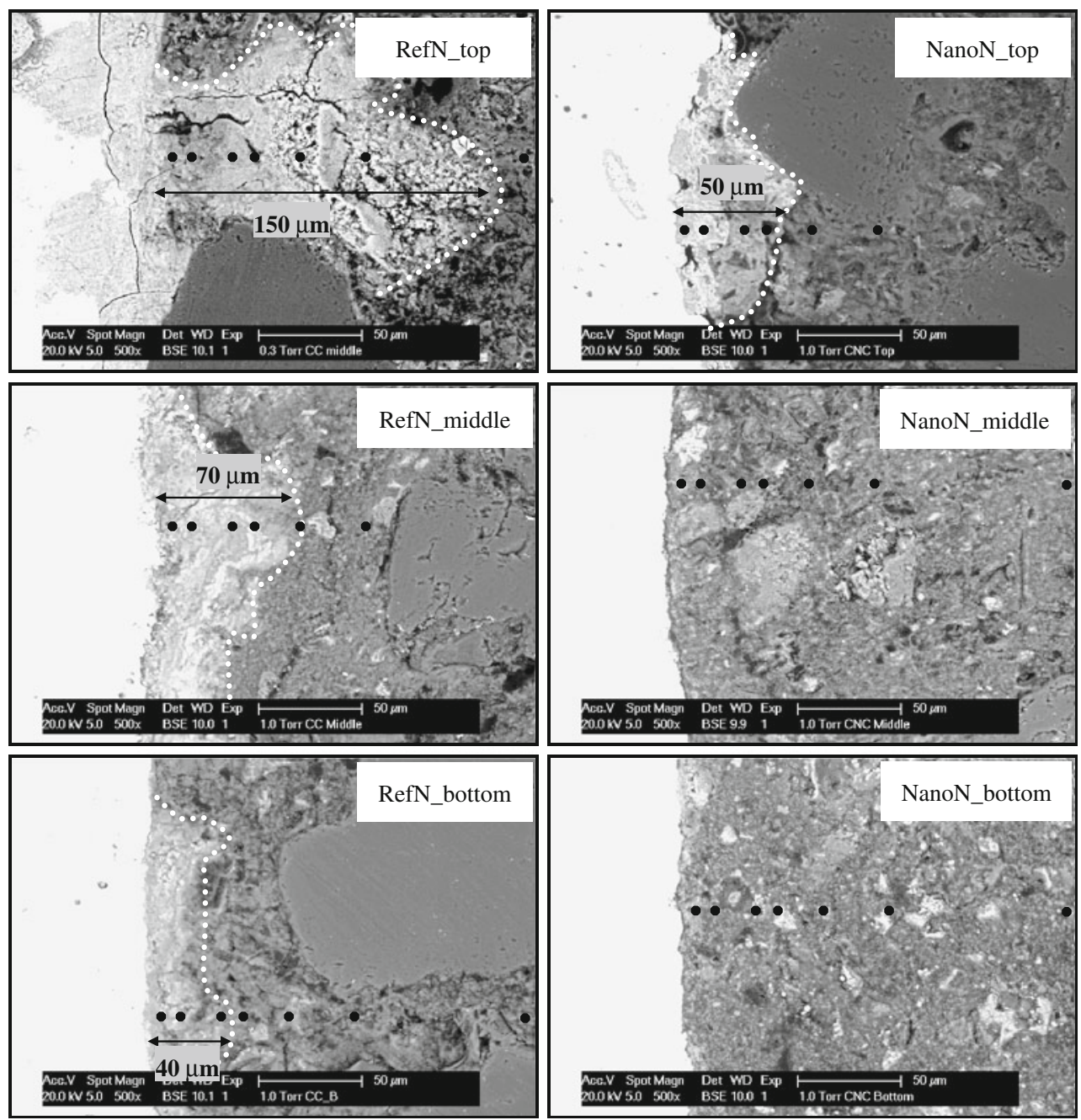

analysis, and microstructure, it seems that the micelles were not able to significantly improve the corrosion resistance of reinforced mortar. However, the above results do not explain the fact that corrosion products are minimal or none for specimen NanoN (Fig. 10). Logically, electrochemical methods will detect corrosion activity and according to EIS and PDP, specimen NanoN was considered as a corroding such. The corrosion damage in the specimen NanoN, however, was part of the initiation process only, whereas further corrosion activity was halted in the presence of micelles. This is a fact, proved by microscopical observation of the steel/cement paste interface throughout the mortar cylinders (bottom, middle, and top cross sections in height of the specimens) and also supported by EDX spot analysis in a radial direction from the steel bar and into the bulk matrix, showing higher chloride concentration in the micelle-containing NanoN compared to specimen RefN. In other words, higher chloride concentration would normally denote for higher corrosion damage, which was actually not the case hereby.
Figure 10 depicts a comparison of steel/cement paste interface for bottom, middle, and top sections of the corroding specimens RefN and NanoN. For the micelles-free specimen RefN, well-distinguished corrosion products were observed at each section of the cylinder, indicating that corrosion products were accumulated on the steel surface and penetrated into the cement matrix. The thickness of the corrosion products accumulated on the steel surface at each section was increasing in the order: bottom section $(40 \mu \mathrm{m})<$ middle section $(70 \mu \mathrm{m})<$ top section $(150 \mu \mathrm{m})$. The amount of corrosion products is closely related to the microstructure and oxygen availability at steel surface. As a result from conditioning in the corrosion medium (the cylinders were half immersed in the testing solution), the bottom and the middle sections of the specimen have a slightly lower porosity compared with the top aerated section. Due to microstructural properties and capillary suction, chlorides were present in higher concentration in the top section of the specimen. For the micellescontaining specimen NanoN, corrosion products were only 
detected at the top section of the cylinder and no corrosion product was observed both at the middle and at the bottom sections. Further, at the top section, the amount of corrosion products was also significantly lower for specimen NanoN, compared to specimen RefN, evidenced by the thinner product layer observed for specimen NanoN (50 $\mu \mathrm{m}$ for specimen NanoN and $170 \mu \mathrm{m}$ for specimen RefN).

The morphological observation at the steel/cement paste interface was also well supported by the EDX spot analysis (the locations for EDX spot analysis were marked as "•" in the images in Fig. 10). The EDX spot analysis was conducted in four radial directions at top, middle, and bottom sections, respectively, and the average iron and chloride concentration at each section for all specimens are summarized in Fig. 11. For the control specimens RefW and
NanoW, very low concentrations of iron and chloride were detected, meaning no corrosion products were accumulated on the steel surface. For the corroding specimens, very high amount of iron was detected at the vicinity of steel bar for specimen RefN, which is consistent with the corrosion products accumulated on the steel surface, evidenced by the morphology observation (Fig. 10). For micelles-containing specimen, except for the top section, very low concentration of iron was detected at the vicinity of steel bar. Figure 11 also shows that at the top section, the chloride concentration for specimen RefN was significantly higher, compared to specimen NanoN, which is well in line with the much more pronounced accumulation of corrosion products for specimen RefN. At the middle and at the bottom sections, the chloride concentration for specimen
Fig. 11 Iron and chloride concentration from steel surface to bulk matrix for all specimens at top, middle, and bottom sections after conditioned for 86 days
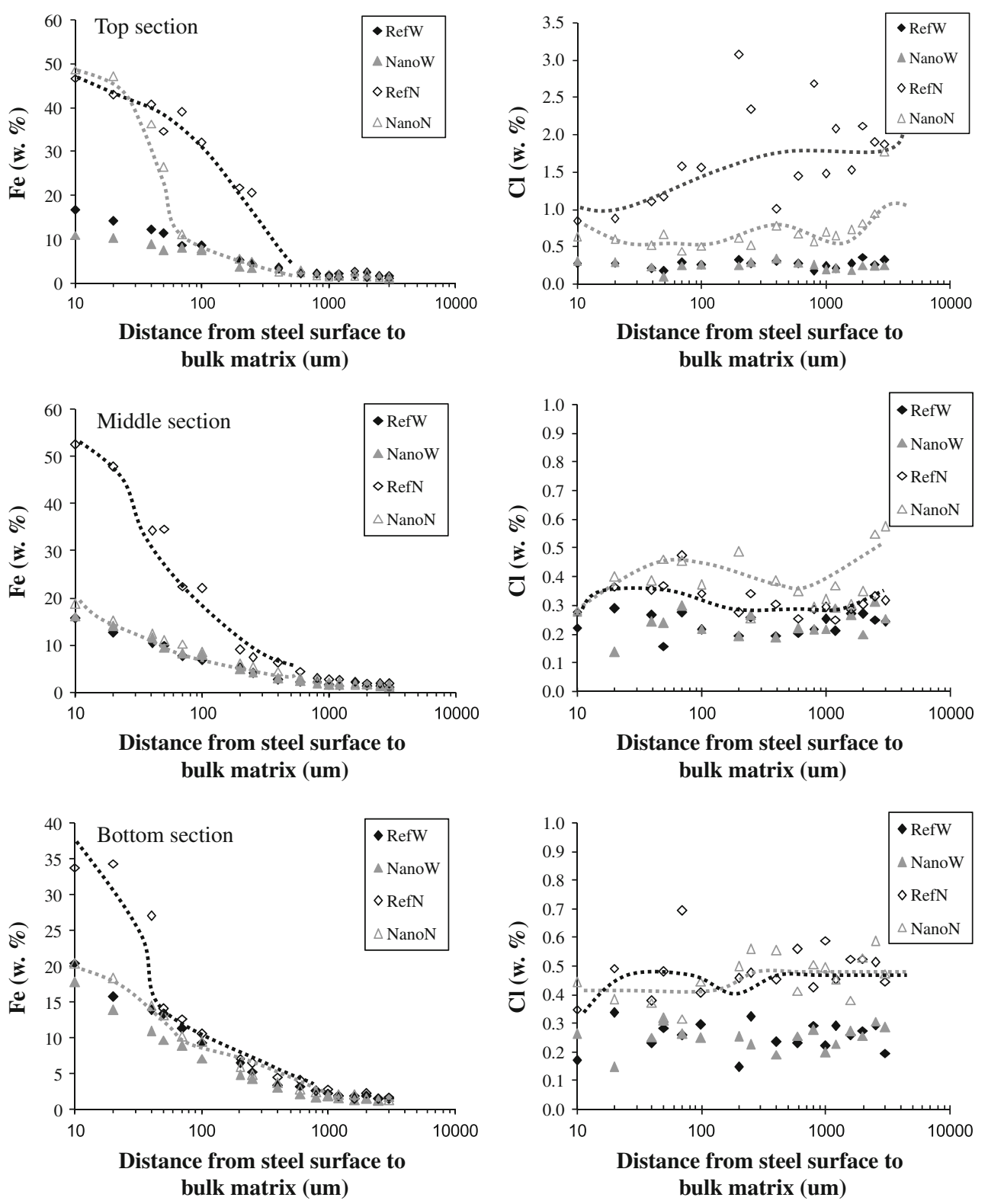
NanoN was similar or even higher than specimen RefN, although no corrosion products were observed. This indicates that for specimen NanoN, initially higher amount of chlorides reached the steel surface and corrosion was initiated at the top section. Apparently, the chloride-binding properties of the cement paste matrix were more pronounced in the presence of micelles. Therefore, at middle and bottom sections, the high amount of chlorides did not lead to corrosion initiation of the steel; at the top section, corrosion propagation was also much less pronounced, compared to specimen RefN. The explanation is related to the effect of the admixed micelles on the formation of hydration products and chloride-binding capacity of the cement-based materials.

The effect of admixed micelles on the chloride-binding capacity of cement-based materials

It is well known that chlorides penetrating into the concrete matrix are partially retained as follows: chlorides may be chemically bound with un-hydrated cement particles (i.e., tricalcium aluminate $\left(\mathrm{C}_{3} \mathrm{~A}\right)$ and calcium ferroaluminate $\left.\left(\mathrm{C}_{4} \mathrm{AF}\right)\right)$ to form Friedels salt $\left(\mathrm{Ca}_{3} \mathrm{Al}_{2} \mathrm{O}_{6} \cdot \mathrm{CaCl}_{2} \cdot 10 \mathrm{H}_{2} \mathrm{O}\right)$ [56-59]; on the other hand, chlorides can also be bound by hydration products [i.e., $\mathrm{CSH}$ and monosulfate aluminate hydrate $(\mathrm{AFm})$ or ettringite $(\mathrm{AFt})]$, either through chemical binding or physical adsorption [59-61]. In order to verify the influence of admixed micelles on the chloride-binding capacity of cement-based materials, the microstructure and the hydration products distribution of cement paste (with the same $w / c$ of 0.5 as for reinforced mortar) were also examined by ESEM and nano-indentation at 7 days hydration age.

Figure 12 shows micrographs of the bulk matrix for both micelle-free specimen OPC and micelle-containing specimen $\mathrm{OPCm}$ at 7 days hydration age. The microstructure of cement paste was improved by the admixed micelles, evidenced by a relatively denser matrix for specimen OPCm, compared to specimen OPC. These visual observations are further confirmed by nano-indentation tests. Figure 13 presents the maps of elastic modulus $E$ of the tested area in the cement paste, together with the corresponding ESEM images (within the rectangular area in the ESEM images). The highest value of the modulus is generally detected in the core of the un-hydrated cement particles; the modulus gradually decreased from the un-hydrated particles into the matrix of cement hydration products with the modulus value between 20 and $40 \mathrm{GPa}[62,63]$; The lowest modulus values (i.e., $0-15 \mathrm{GPa}$ ) were related to the pores in the matrix.

Normally, two types of CSH exist in cement paste: highdensity (HD) CSH (formed around the un-hydrated cement particles with modulus of 29.1-31.4 GPa) and low-density (LD) $\mathrm{CSH}$ (formed in the matrix with modulus of 18.2-23.4 GPa) [64-66]. According to the modulus maps (Fig. 13), the admixed micelles did not lead to significant influence on the formation of HD CSH for cement paste. However, for specimen OPCm, a much larger area corresponding to a modulus value between 15 and $30 \mathrm{GPa}$ was observed, indicating a more uniform distribution of $\mathrm{LD}$ $\mathrm{CSH}$; the area corresponding to the pores in the matrix (i.e., area with modulus value between 0 and $15 \mathrm{GPa}$ ) was smaller for specimen $\mathrm{OPCm}$ and significantly larger for specimen OPC. The results reveal that the admixed micelles lead to a more uniform distribution of hydration products and a denser matrix for the cement paste which is due to the role of micelles, acting as nucleation sites for the formation of new hydration products [25, 67]. These outcomes are consistent with a previous study in plain mortar [22], where the presence of $\mathrm{PEO}_{113}-b-\mathrm{PS}_{218}$ micelles did not significantly affect the amount of un-hydrated cement particles but influenced the CSH "network": higher amounts of CSH was obtained for the micelles-containing specimen. Therefore, the more uniform distribution of hydration products combined with the higher amount of LD CSH lead to a higher chloride-binding capacity in the cement paste in the presence of micelles. It was also reported that the PS-containing polymers promote the formation of calcium aluminate trisulfate hydrate phases (AFt) and facilitate chloride binding in cement paste [68].
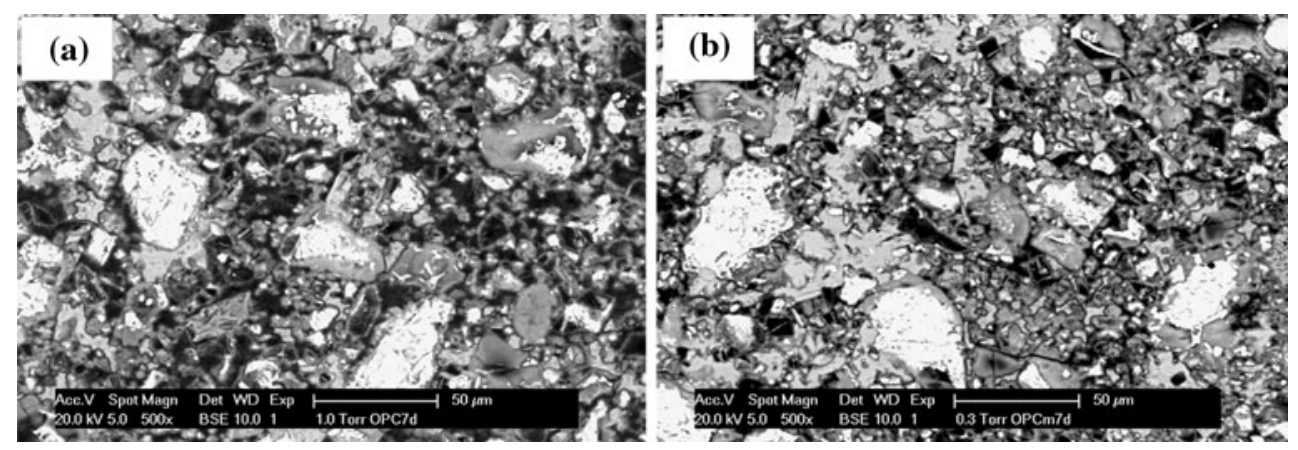

Fig. 12 Cement paste matrix at $\times 500$ magnification at 7 days curing age. Specimens a OPC and b OPCm 


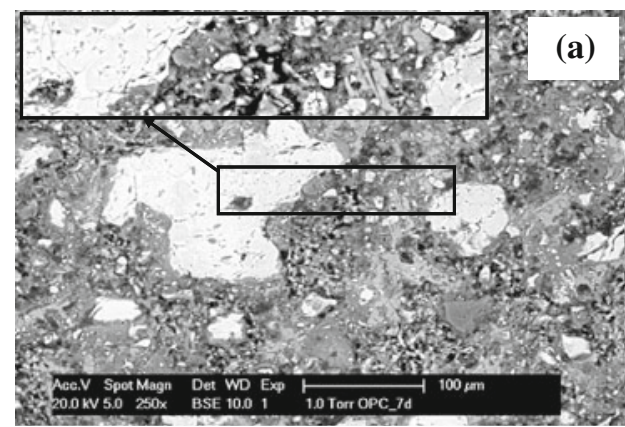

$\mathrm{E}(\mathrm{GPa})$

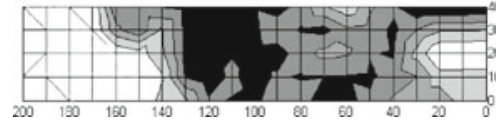

Distance (um)

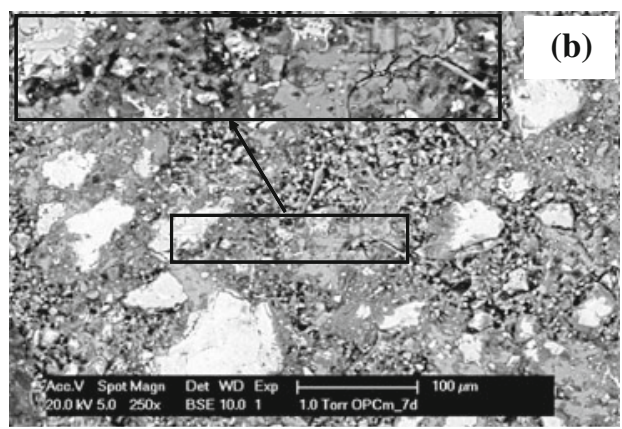

$\mathrm{E}(\mathrm{GPa})$

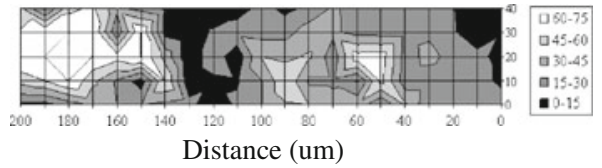

Fig. 13 Maps of elastic modulus $E$ of the test area in cement paste, together with the corresponding ESEM images (marked rectangular areas corresponds to the modulus maps). Specimens a OPC_7d and b OPCm_7d

Therefore, based on the experimental results and the reported studies, it can be stated as follows: when micelles are admixed in cement-based materials, the chloridebinding capacity of the cement matrix is increased resulting from the higher amount of $\mathrm{CSH}$ and $\mathrm{AFt}$ phases and more uniform distribution of hydration products; further, for the micelles-containing specimens, corrosion initiation was minimal or none and after corrosion was initiated, further corrosion propagation was halted by the admixed micelles.

\section{Conclusions}

In order to investigate the influence of polymeric nanoaggregates on the corrosion performance of reinforced mortar, a very low concentration $(0.025 \mathrm{wt} \%$ of dry cement) of $\mathrm{PEO}_{113}-b$ - $\mathrm{PS}_{70}$ micelles was admixed in reinforced mortar cylinders. This micelle concentration was not able to significantly improve the corrosion resistance of the steel reinforcement, evidenced by the similar electrochemical response: a close (active) behavior was observed for micelles-free and micelles-containing specimens. Further, the similar microstructural properties for specimens RefN and NanoN determine similar permeability and access to chloride penetration. Surface analysis shows formation and accumulation of corrosion products on the steel surface for both specimens RefN and NanoN, however, the product layer in specimen $\mathrm{NanoN}$ is with a higher corrosion resistance, consisting of $\mathrm{Fe}_{2} \mathrm{O}_{3}, \mathrm{Fe}_{3} \mathrm{O}_{4}$, and Casubstituted such, i.e., a composition that favors steel (re)passivation. Additionally, the microscopical observations at the steel cement/paste interface throughout the reinforced mortar show a positive effect of the admixed micelles: corrosion products were minimal or none in specimen NanoN, although the chloride concentration in the cement matrix was even higher, compared to specimen RefN.

These results indicate that the hereby recorded positive effect of micelles, admixed in reinforced mortar, is related to the combination of several phenomena, namely: a steel surface product layer with enhanced corrosion resistance (evidenced by surface analysis); a more uniform distribution of bulk matrix hydration products (evidenced by nanoindentation); increased chloride-binding capacity for the micelles-modified matrix (as evidenced by microstructural observations and EDX analysis). To this end, the corrosion damage was part of an initiation phase only, whereas further corrosion propagation was halted by the admixed micelles.

Open Access This article is distributed under the terms of the Creative Commons Attribution License which permits any use, distribution, and reproduction in any medium, provided the original author(s) and the source are credited.

\section{References}

1. Broomfield J (1997) Corrosion of steel in concrete, understanding, investigating and repair. Spon, London

2. Şahmaran M (2007) J Mater Sci 42:9131. doi:10.1007/s 10853-007-1932-Z

3. Elsener B (2002) Cem Concr Compos 24(1):65

4. Garces A, Andrade MC, Saez A, Alonso MC (2005) Corros Sci 47(2):289

5. Uhlig HH (2000) In: Revie RW (ed) Uhlig's corrosion handbook. Wiley, Ottawa, p 583

6. Bertolini L, Elsener B, Pedeferri P, Polder R (2004) Corrosion of steel in concrete: prevention, diagnosis, repair, 1st edn. Wiley, Weinheim

7. Petterson K (1994) In: Swamy RN (ed) Corrosion and corrosion protection of steel in concrete. Academic Press, Sheffield, p 461 
8. Tuutti K (1982) Corrosion of steel in concrete. Swedish Cement and Concrete Research Institute, Stockholm

9. Chang T, Shih J, Yang K (2007) J Mater Sci 42:7478. doi: 10.1007/s10853-006-1462-0

10. Hui L, Xiao HG, Ou JP (2004) Cem Concr Res 34:435

11. Shebl SS, Allie L, Morsy MS, Aglan HA (2009) J Mater Sci 44:1600. doi:10.1007/s10853-008-3214-9

12. Zhang MH, Li H (2011) Constr Build Mater 25(2):608

13. Tao J (2005) Cem Concr Res 35:1943

14. Li H, Xiao H, Yuan J, Ou J (2003) Composites B 35:185

15. Jayapalan AR, Lee BY, Fredrich SM, Kurtis KE (2010) Transp Res Rec 2141:41

16. Land G, Stephan D (2012) J Mater Sci 47:1011. doi:10.1007/s 10853-011-5881-1

17. Sanchez F, Sobolev K (2010) Constr Build Mater 24:2060

18. Etteyeb N, Dhouibi L, Sanchez M, Alonso C, Andrade C, Triki E (2007) J Mater Sci 42:4721. doi:10.1007/s10853-006-0880-3

19. Wombacher F, Maeder U, Marazzani B (2004) Cem Concr Compos 26:209

20. Elsener B, Büchler M, Stalder F, Böhni H (1999) Corrosion 55(12): 1155

21. Koleva DA, Ye G, Zhou J, Petrov P, van Breugel K (2008) International conference on microstructure related durability of cementitious composites, Nanjing, China, 13-15 October, 2008, RILEM Publications SARL, p 161

22. Koleva DA, van Breugel K, Ye G, Zhou J, Chamululu G, Koenders E (2009) In: Proceedings of the ACI fall meeting "nanotechnology of concrete: the next big thing is small

23. Koleva DA, van Breugel K, Boshkov N, Mol JMC, de Wit JHW (2010) ECS Trans 25(24):79

24. Hu J, Koleva DA, de Wit JHW, Kolev H, van Breugel K (2011) J Electrochem Soc 158(3):C76

25. Hu J, Koleva DA, van Breugel K (2010) 2nd international symposium on service life design for infrastructure (SLD2010), 4-6 October, Delft, The Netherlands. RILEM Publications SARL 70(2):791-797

26. Koleva DA, van Breugel K, de Wit JHW, van Westing E, Boshkov N, Fraaij ALA (2007) J Electrochem Soc 154(3):E45

27. Koleva DA, Hu J, Fraaij ALA, Stroeven P, Boshkov N, de Wit JHW (2006) Corros Sci 48:4001

28. Hu J (2004) Porosity of concrete, morphological study of model concrete. PhD thesis, Delft University of Technology, Delft

29. Ye G (2003) Experimental study and numerical simulation of the development of the microstructure \& permeability of cementitious materials. PhD thesis, Delft University of Technology, Delft. http://Microlab.citg.tudelft.nl

30. Matyjaszewski K, Xia J (2001) J Chem Rev 101:2921

31. Eichhorn SJ, Dufresne A, Aranguren M, Marcovich NE, Capadona JR, Rowan SJ, Weder C, Thielemans W, Roman M, Renneckar S, Gindl W, Veigel S, Keckes J, Yano H, Abe K, Nogi M, Nakagaito AN, Mangalam A, Simonsen J, Benight AS, Bismarck A, Berglund LA, Peijs T (2010) J Mater Sci 45:1. doi: 10.1007/s10853-009-3874-0

32. Chang L, Wu S, Chen S, Li X (2011) J Mater Sci 46:2024. doi: 10.1007/s10853-010-5033-Z

33. Hu J, Stroeven P (2003) Image Anal Stereol 22:97

34. Koleva DA, van Breugel K, de Wit JHW, van Westing E, Copuroglu O, Fraaij ALA (2008) Mater Charact 59:801

35. Koleva DA (2007) Corrosion and Protection in Reinforced Concrete, PhD Thesis, Delft University of Technology. Delft. http://Microlab.citg.tudelft.nl
36. Koleva DA, Hu J, Fraaij ALA, van Breugel K, de Wit JHW (2007) Cem Concr Res 37(4):604

37. Stroeven P, Hu J, Koleva DA (2010) Cem Concr Compos 32:291

38. Oliver WC, Pharr GM (2004) J Mater Res 19(1):3

39. Alonso C, Castellote M, Andrade C (2002) Electrochim Acta 47:3469

40. Miranda JM, González JA, Cobo A, Otero E (2006) Corros Sci 48:2172

41. Aperador W, Mejía de Gutiérrez R, Bastidas DM (2009) Corros Sci $51: 2027$

42. Ford SJ, Shane JD, Mason TO (1998) Cem Concr Res 28(12): 1737

43. Poupard O, Ait-Mokhtar A, Dumargue P (2003) J Mater Sci 38:3521. doi:10.1023/A:1025600624991

44. Dhouibi L, Refait P, Triki E, Genin JMR (2006) J Mater Sci 41:4928. doi:10.1007/s10853-006-0332-0

45. Andrade C, Keddam M, Nóvoa XR, Pérez MC, Rangel CM, Takenouti H (2001) Electrochim Acta 46:3905

46. Cabeza M, Merino P, Miranda A, Nóvoa XR, Sanchez I (2002) Cem Concr Res 32:881

47. MacDonald JR (1987) Impedance spectroscopy: emphasizing solid materials and systems. Wiley, New York

48. Poupard O, Ait-Mokhtar A, Dumargue P (2003) J Mater Sci 38:2845. doi:10.1023/A:1024428317968

49. Sagüés AA, Pech-Canul MA, Shahid Al-Mansur AKM (2003) Corros Sci 45:7

50. Feliú F, González JA, Feliú S (2004) J Electrochem Soc 151:B134

51. Zoltowski P (1998) J Electroanal Chem 443:149

52. Andrade C, Soler L, Alonso C, Nóvoa RX, Keddam M (1995) Corros Sci 37:2013

53. Poupard O, Aït-Mokhtar A, Dumargue P (2004) Cem Concr Res 34:991

54. Poupard O, L'Hostis V, Catinaud S, Petre-Lazar I (2006) Cem Concr Res 36:504

55. Huet B, L'Hostis V, Miserque F, Idrissi H (2005) Electrochim Acta 51:172

56. Chudek JA, Hunter G, Jones MR, Scrimgeour SN, Hewlett PC, Kudryavtsev AB (2000) J Mater Sci 35:4275. doi:10.1023/A: 1004824100029

57. Gaal GCM (2004) Prediction of deterioration of concrete bridges. $\mathrm{PhD}$ thesis, Delft University of Technology, Delft

58. Iñiguez-Sánchez C, Gómez-Zamorano L, Alonso M (2012) J Mater Sci. doi:10.1007/s10853-011-6210-4

59. Justnes H (1996) A review of chloride binding in cementitious systems. Trondheim, Norway

60. Yuan Q, Shi C, Schutter G, Audenaert K, Deng D (2009) Constr Build Mater 23(1):1

61. Beaudoin JJ, Ramachandran VS, Feldman RF (1990) Cem Concr Res 20(6):875

62. Constantinides G, Ulm FJ, van Vliet K (2003) Mater Struct $36: 191$

63. Hughes JJ, Trtik P (2004) Mater Charact 53:223

64. Jennings HM (2000) Cem Concr Res 30(1):101

65. Tennis PD, Jennings HM (2000) Cem Concr Res 30(6):855

66. Constantinides G, Ulm F (2004) Cem Concr Res 34:67

67. Silva DA, Monteiro PJM (2005) Cem Concr Res 35:351

68. Yang Z, Shi X, Creighton AT, Peterson MM (2009) Constr Build Mater 23:2283 